\title{
REVIEW
}

\section{Review of the direct thermochemical conversion of lignocellulosic biomass for liquid fuels}

\author{
Jianchun JIANG (凶), Junming XU, Zhanqian SONG \\ Institute of Chemical Industry of Forestry Products, CAF; Key Laboratory of Biomass Energy and Material, National Engineering \\ Laboratory for Biomass Chemical Utilization; Key Laboratory of Forest Chemical Engineering, SFA, Nanjing 210042, China
}

\begin{abstract}
Increased demand for liquid transportation fuels, environmental concerns and depletion of petroleum resources requires the development of efficient conversion technologies for production of second-generation biofuels from non-food resources. Thermochemical approaches hold great potential for conversion of lignocellulosic biomass into liquid fuels. Direct thermochemical processes convert biomass into liquid fuels in one step using heat and catalysts and have many advantages over indirect and biological processes, such as greater feedstock flexibility, integrated conversion of whole biomass, and lower operation costs. Several direct thermochemical processes are employed in the production of liquid biofuels depending on the nature of the feedstock properties: such as fast pyrolysis/liquefaction of lignocellulosic biomass for bio-oil, including upgrading methods, such as catalytic cracking and hydrogenation. Owing to the substantial amount of liquid fuels consumed by vehicular transport, converting biomass into drop-in liquid fuels may reduce the dependence of the fuel market on petroleumbased fuel products. In this review, we also summarize recent progress in technologies for large-scale equipment for direct thermochemical conversion. We focus on the technical aspects critical to commercialization of the technologies for production of liquid fuels from biomass, including feedstock type, cracking catalysts, catalytic cracking mechanisms, catalytic reactors, and biofuel properties. We also discuss future prospects for direct thermochemical conversion in biorefineries for the production of high grade biofuels.
\end{abstract}

Keywords lignocellulosic biomass, thermochemical, liquid fuels, upgrading, biofuels

Received February 25, 2015; accepted March 20, 2015

Correspondence: bio-energy@163.com

\section{Introduction}

In 2011 the world annual primary energy consumption was estimated at over $13 \mathrm{Mt}$ of oil equivalent ${ }^{[1]}$. Fossil fuels account for $82 \%$ of the primary energy consumption, with oil (32\%), coal (29\%) and natural gas $(21 \%)$ as the major fuels in $2011^{[1]}$. Energy consumption worldwide has never been higher due to increasing population and the development of societies worldwide ${ }^{[1,2]}$.

Transportation is one of the major energy consumption sectors and it accounts for about one fifth of the total energy consumed worldwide ${ }^{[3]}$. As the world's population grows and means of transportation becomes more readily available, the need for fuels, especially liquid fuels, will increase $^{[4]}$. However, progressive depletion of petroleumbased fuels has led to a global energy crisis $^{[5]}$. The decreasing availability of petroleum resources is coupled with an increasing emission of greenhouse gases that are responsible for global warming. Therefore, there is a great need for methods that can decrease greenhouse gas emissions, and this has led to an increasing interest in biofuels.

Substantial research has been undertaken to find alternative fuels to replace gasoline and diesel. The optimal solution would be an alternative which is equivalent to current fuels, i.e., ones that are compatible with the infrastructure as we know it, but also fuel which is sustainable and will decrease the $\mathrm{CO}_{2}$ emission and thereby decrease the man-made environmental footprint ${ }^{[6]}$.

Renewable biomass sources can be converted to environmentally friendly fuels and are a logical choice to produce fuel oil. It is clean, for it has negligible content of sulfur, nitrogen and ash, and gives lower emissions of $\mathrm{SO}_{2}$, $\mathrm{NO} x$ and soot than most fossil fuels. Zero net emission of $\mathrm{CO}_{2}$ can be achieved because $\mathrm{CO}_{2}$ released from biomass will be quantitatively recycled into plants by photosynthesis.

To derive more energy from renewable feedstocks, the 
USA and other countries set up a domestic program/ strategy for renewable fuels in order to decrease their dependence on imported petroleum. In February 2010, the US Environmental Protection Agency (EPA) finalized regulations under the Energy Independence and Security Act of 2007 that make significant changes to the renewable fuel standard in the Energy Policy Act of 2005. The changes aim to boost domestic biofuel production by expanding the volume of renewable fuel sold for transportation in the USA.

The targets set by the European Union renewable road map expect that member states substitute $20 \%$ of their fuels for biofuels by $2020^{[7]}$. Other developing countries, such as China, also set up a road map for the Development of Renewable Energy by National Development and Reform Commission in 2007. This road map requires the total replacement of $20 \%$ of liquid fuels with biofuels by $2020^{[8]}$.

Although the use of biofuels has shown a steady growth in recent years, it still only represents $3 \%$ of global transport fuel consumption ${ }^{[9]}$. About $97 \%$ of all transportation energy in the USA is derived currently from nonrenewable petroleum. Energy for transportation consumes $63 \%$ of all oil used in the USA. Imported oil accounts for more than half of all oil used in the USA ${ }^{[10]}$.

Liquid biofuels under current development include biodiesel in the European Union and bio-ethanol in China. Total European Union biodiesel production for 2010 was over $9.5 \mathrm{Mt}$, an increase of $5.5 \%$ from $2009^{[11]}$. The production of bio-ethanol in China was $2 \mathrm{Mt}$ in $2011^{[12]}$. However, these biofuels are produced mainly from biomass suitable for food, such as starch, sugar and triglycerides (e.g., animal fats and vegetable oil), usually called first generation biofuels.

The second generation technologies for the production of fuels from non-food biomass have the great potential to solve the problems of first generation biofuels. These feedstocks include forestry and agricultural residues (e.g., woody biomass, straw, bagasse and corn stover), wastes (e.g., paper, manures and sawmill residues $)^{[3-5]}$. These feedstocks have no competition with human food and cultivated land and, at the same time, can solve some environmental problems caused by waste organic materials.

Thermochemical conversion is a major method for production of second generation liquid biofuels from nonfood biomass. As the term implies, thermochemical conversion involves the use of heat to change biomass from solid to other forms. The process has several advantages over biological processes, including greater feedstock flexibility, conversion of both carbohydrate and lignin into products, faster reaction rates, and feasible to transport it. At the same time, biomass feedstock involves interactions with catalyst/chemical reactants to transform basic molecular structures into those more similar to useable fuels.
This review will give an overview of the current status of direct thermochemical processes for production of liquid biofuels. Aspects of different raw materials, operating conditions, choice of catalyst, and reaction mechanisms will be discussed. The molecular structures changing during the thermochemical processes will be considered as an important indicator for the quality of biofuels. The properties of the products from biomass are benchmarked against petroleum-based fuels. Finally, production of dropin biofuels through thermochemical processing at an industrial scale is discussed.

\section{Thermochemical processing of lignocellulosic biomass}

Figure 1 shows the reaction pathway for production of liquid biofuels from lignocellulosic biomass. Usually the pyrolytic oil needs an upgrading process because the fuel properties are relatively low compared with petroleum fuels. The upgrading process might be a separate operation. It can also be coupled with thermochemical reactions during the processing. Biochar is usually generated from this process as a result of the dehydration reaction and condensation of the liquid products. There are two major thermochemical processes for converting lignocellulosic biomass into liquid fuels: pyrolysis and liquefaction. Both routes will be discussed individually below.

\subsection{Processing properties of lignocellulosic biomass}

Lumber production in the forestry products industry alone provides sufficient lignocellulosic materials since approximate $40 \%$ of the timber becames solid waste. Take China for example, there are $109 \mathrm{Mt}$ of lignocellulosic waste from intermediate cutting annually, $42 \mathrm{Mt}$ of lignocellulosic residue from lumber production, and municipal waste (waste furniture) $60 \mathrm{Mt}$. These waste lignocellulosic materials have great potential for energy use.

Table 1 shows the main composition of typical lignocellulosic biomass. As shown in Table 1, lignocellulosic biomass is significantly different from petroleumbased fuels. Lignocellulosic biomass normally consists of cellulose, hemicellulose and lignin, in the proportions $35 \%-50 \%, 15 \%-25 \%$ and $15 \%-30 \%$, respectively. The oxygen content of raw material is usually $40 \%-50 \%$, which primarily comes from the bonded oxygen in cellulose and lignin. Cellulose is made of linear chains of D-glucose units linked by $\beta$-(1-4)-glucosidic bonds, while the lignin is made of phenolic units. It is a big challenge to remove the oxygen atoms from their molecular structures to reach an elemental composition similar to fossil fuels.

Thermochemical conversion can accelerate the deoxygenation reactions of lignocellulosic biomass. Basically, the petroleum crude oils are from the biomass feedstock of 


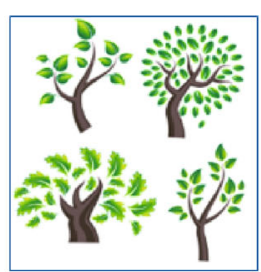

Lignocellulosic materials
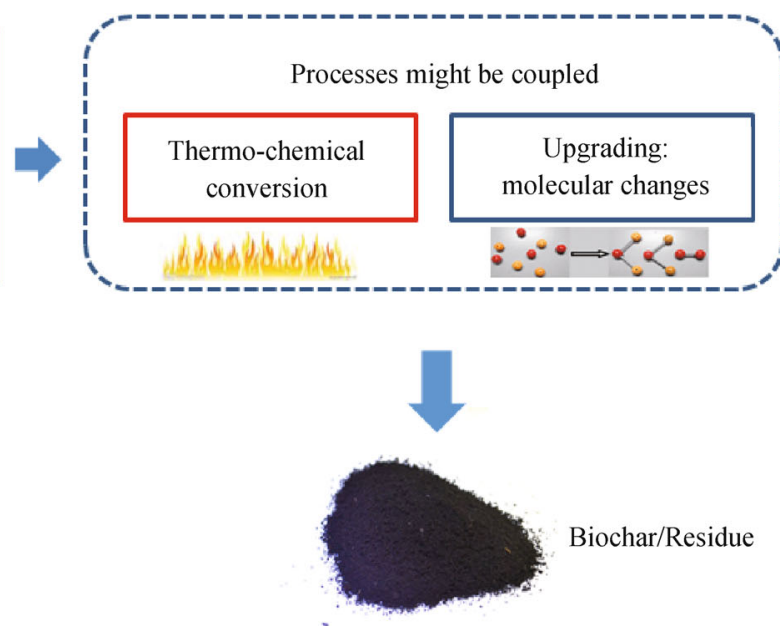

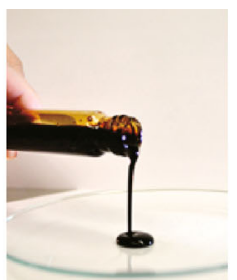

Pyrolytic/Liquefied

oil

Fig. 1 The reaction pathway for thermochemical processing of lignocellulosic biomass

Table 1 Comparison of lignocellulosic biomass and petroleum heavy fuel oil ${ }^{\mathrm{a}}$

\begin{tabular}{lcccc}
\hline \multirow{2}{*}{ Composition } & \multicolumn{3}{c}{ Percentage/\% } \\
\cline { 2 - 5 } Moisture & Poplar & Sawdust & Bamboo & Heavy fuel oil ${ }^{[13]}$ \\
Ash & 8.29 & 9.04 & 10.02 & 0.1 \\
Benzene-ethanol extractives & 1.34 & 1.04 & 1.48 & 0.1 \\
Lignin & 5.20 & 2.41 & 3.26 & - \\
Cellulose & 16.45 & 21.36. & 27.02 & - \\
Hemicellulose & 42.82 & 50.62 & 43.21 & - \\
C & 25.61 & 24.83 & 24.88 & \\
Element analysis H & 46.61 & 47.72 & 46.82 & \\
O & 6.63 & 6.98 & 4.23 & \\
\hline
\end{tabular}

Note: 'All the lignocellulosic biomass samples were tested in the authors' laboratory.

millions of years ago. These biomass materials went through deoxygenation reactions under high pressure at elevated temperatures deep inside the earth. After the slow conversion process, the molecular structures of the biomass were changed to petroleum crude oil. Thermochemical conversion studies focus on the relationship between the change of molecular structures and the reaction parameters (heat and pressure), mimicking the reactions taking place during the formation of petroleum oil. The fundamental hypothesis is that thermochemical conversion can realize rearrangement of molecular structures of lignocellulosic biomass to form high grade biofuels comparable to petroleum fuels.

\subsection{Pyrolysis of lignocellulosic biomass for liquid fuels}

\subsubsection{Fast pyrolysis}

Fast pyrolysis is a method that can convert solid lignocellulosic biomass to a liquid product known as pyrolytic oil or bio-oil. Using carefully controlled fast pyrolysis conditions (reaction temperature of around $500^{\circ} \mathrm{C}$, vapor phase temperature of $400-450^{\circ} \mathrm{C}$, and short vapor residence times of typically $<2 \mathrm{~s}$ ), it is possible to generate a bio-oil, generally from whole biomass, in yields of up to $75 \%$ of weight on a dry feed basis $^{[14]}$.

Virtually any form of biomass can be considered for fast pyrolysis. Nearly 100 different types of biomass from agricultural and forestry wastes (such as sawdust and rice husk $)^{[15]}$, have been tested in many laboratories.

Bio-oil generated from fast pyrolysis is a mixture of multiple oxygenated components derived from depolymerization and fragmentation of cellulose, hemicellulose and lignin, mainly composed of carbonxylic acids, alcohols, aldehydes, esters, ketones, sugars, phenols, guaiacols, syringols, furans, lignin derived phenols and extractible organics with multi-functional groups. Typical properties of wood pyrolysis bio-oil are listed in Table 2 .

The presence of high oxygen content is the primary 
Table 2 Typical properties of wood pyrolysis bio-oil and of heavy fuel oil $^{[16]}$

\begin{tabular}{lcc}
\hline Physical property & Bio-oil & Heavy fuel oil \\
\hline Moisture content/\% & $15-30$ & 0.1 \\
$\mathrm{pH}$ & 2.5 & - \\
Specific gravity & 1.2 & 0.94 \\
Elemental composition/\% & & \\
$\mathrm{C}$ & $54-58$ & 85 \\
$\mathrm{H}$ & $5.5-7.0$ & 11 \\
$\mathrm{O}$ & $35-40$ & 1 \\
$\mathrm{~N}$ & $0-0.2$ & 0.3 \\
$\quad$ Ash & $0-0.2$ & 0.1 \\
Higher heating value $/\left(\mathrm{MJ} \cdot \mathrm{kg}^{-1}\right)$ & $16-19$ & 40 \\
Viscosity (at $\left.50^{\circ} \mathrm{C}\right) / \mathrm{cP}$ & $40-100$ & 180 \\
Solids $/ \%$ & $0.2-1.0$ & 1 \\
Distillation residue $/ \%$ & up to 50 & 1 \\
\hline
\end{tabular}

differences between bio-oils and hydrocarbon fuels. The oxygen content of bio-oils is usually $35 \%-40 \%$, distributed in more than 300 compounds depending on the source of biomass and conditions of the pyrolytic processes (temperature, residence time and heating rate). The high oxygen content leads to a lower energy density than fossil fuels by $50 \%$ and immiscibility with hydrocarbon fuels. Bio-oils also have deleterious properties of high viscosity, thermal instability and corrosiveness, which are attributed to the high content of oxygen.

Fast pyrolysis is still in its commercial infancy after having been developed since the early 1980s. To date, the only commercial application is the production of food flavoring chemicals from hardwood via extraction of smoke-flavor components from the pyrolysis oil aqueous phase $^{[14]}$.

However, there has been a considerable growth and expansion of activities over recent decades with more innovation in the types of reactor explored by academic institutions ${ }^{[17]}$. There are three main well known reactor types, the fluid bed reactor (bubbling fluid beds and circulating fluid bed), rotating cone reactor, and ablative fast pyrolysis reactor (Fig. 2).

The term fluid bed reactor refers mainly to a bubbling or circulating fluid bed (Fig. 3). These two types of reactors have many features in common, such as simple construction and operation, good temperature control and very efficient heat transfer to biomass particles. The only difference between them is that a bubbling fluid bed has low gas velocities, which makes hot gas form separated bubbles as it is from the high-density solid feedstock. In contrast, a circulating fluid bed has higher gas velocities, which makes the feedstock disperse uniformly in the pyrolysis reactor.

The University of Waterloo in Canada pioneered the science of fast pyrolysis and established a clear lead in this area for many years ${ }^{[18,19]}$. Fluid beds have been selected for further development by several companies, for example Union Fenosa ${ }^{[20]}$, who built and operated a $200 \mathrm{~kg} \cdot \mathrm{h}^{-1}$ pilot unit in Spain based on the University of Waterloo process (it was dismantled some years ago), and Dynamotive, who operated a $75 \mathrm{~kg} \cdot \mathrm{h}^{-1}$ and $400 \mathrm{~kg} \cdot \mathrm{h}^{-1}$ pilot unit ${ }^{[21]}$ in Canada based on an RTI design and have subsequently built a $100 \mathrm{t} \cdot \mathrm{d}^{-1}$ and a $200 \mathrm{t} \cdot \mathrm{d}^{-1}$ plant in Canada.

The rotating cone reactor, invented at the University of Twente ${ }^{[22]}$ and developed by the British Technology Group $^{[23]}$, is a relatively recent development and effectively operates as a transported bed reactor (Fig. 4). Centrifugation drives hot sand and biomass up a rotating heated cone. The pyrolytic vapors are collected and processed by established methods (Fig. 3). Char and sand drop into a fluid bed surrounding the cone, where they are burned to recover the heat, which is then dropped back into the rotating cone. A $250 \mathrm{~kg} \cdot \mathrm{h}^{-1}$ unit is now operational,

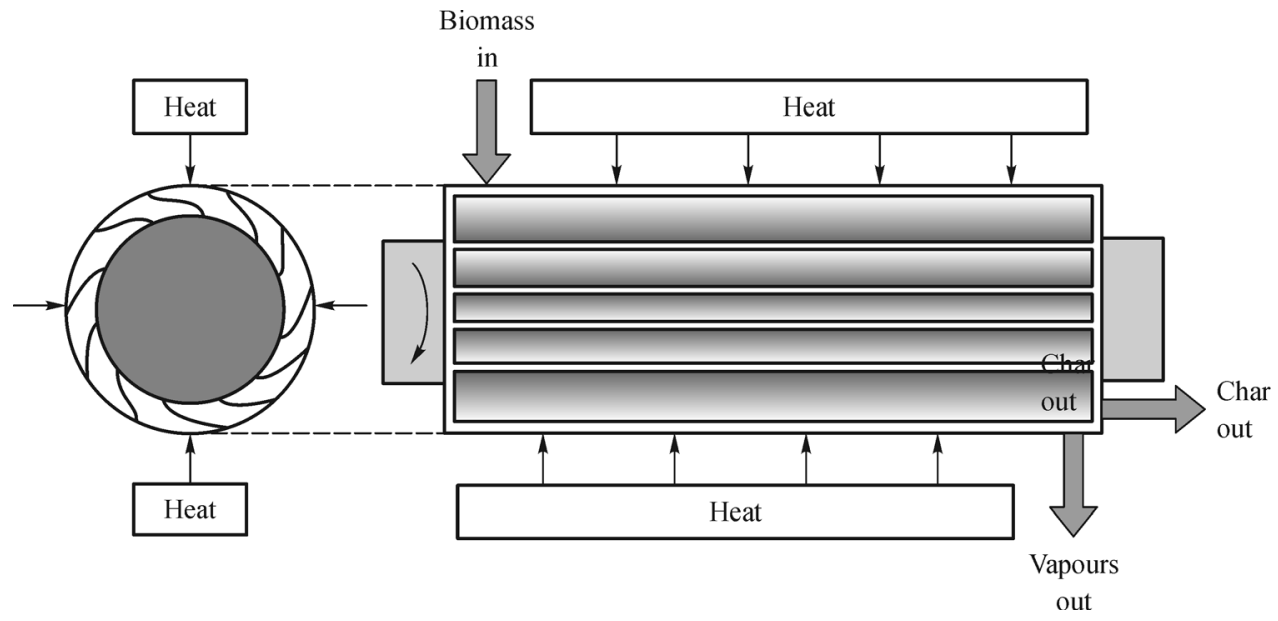

Fig. 2 Aston University Mark 2 ablative fast pyrolysis reactor ${ }^{[17]}$ 


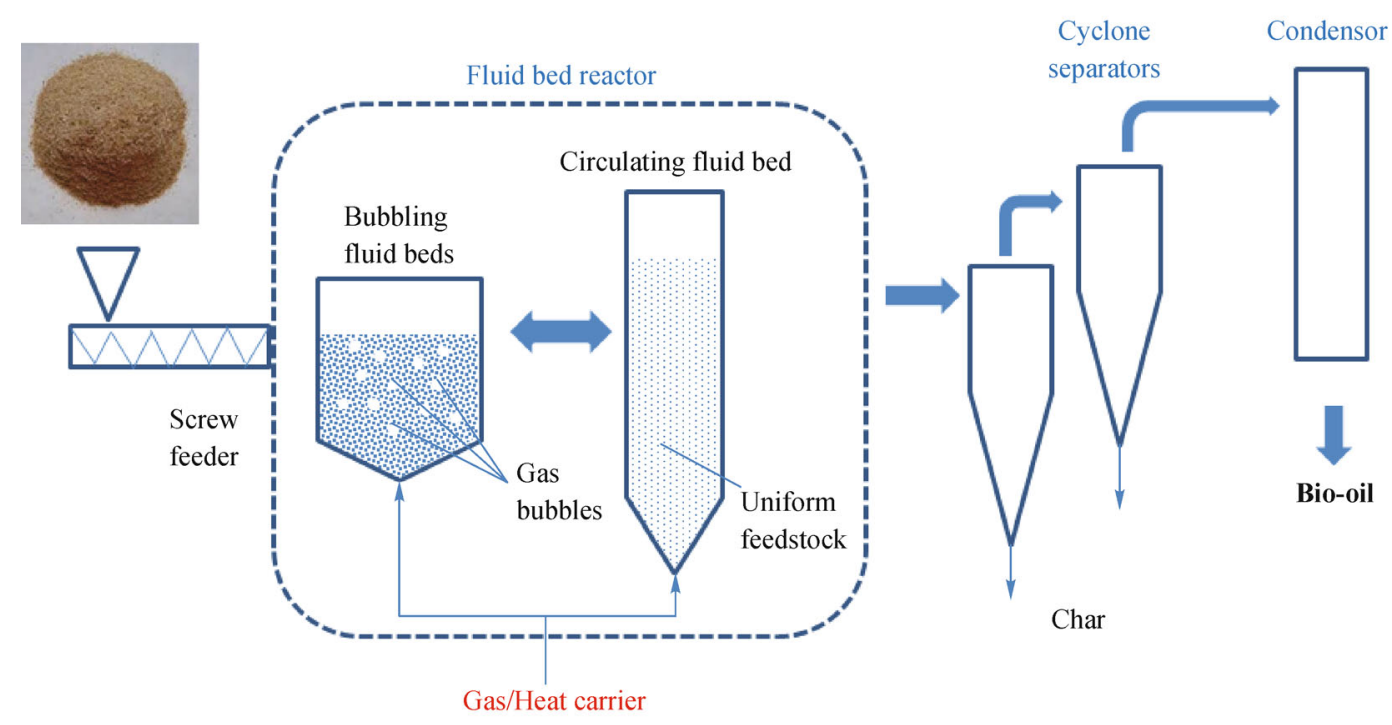

Fig. 3 Main features of bubbling fluid bed and circulating fluid bed

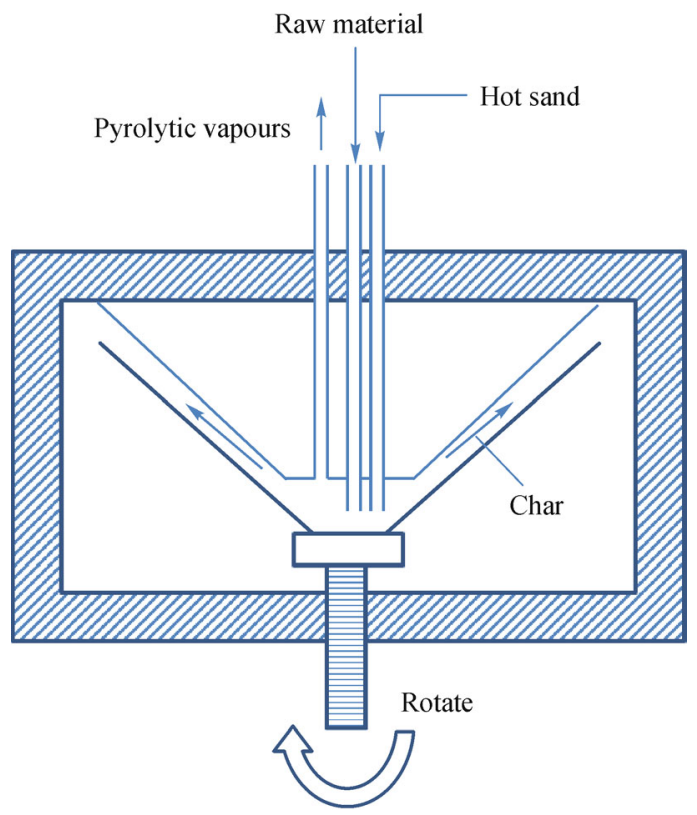

Fig. 4 Rotating cone pyrolysis reactor

and a scaled up version of $50 \mathrm{t} \cdot \mathrm{d}^{-1}$ was commissioned in Malaysia in 2005.

The ablative fast pyrolysis reactor was developed by Aston University ${ }^{[24,25]}$. Ablative pyrolysis is substantially different in concept compared with other methods of fast pyrolysis. The mode of reaction in ablative pyrolysis is like melting butter in a frying pan - the rate of melting can be significantly enhanced by pressing the butter down and moving it over the heated pan surface. As the wood is moved away, the molten layer then vaporizes to a product very similar to that derived from fluid bed systems. Liquid yields of $70 \%-75 \%$ of weight on dry-feed basis are typically obtained.

The pyrolysis reactor requires about $10 \%-15 \%$ of the total capital cost of an integrated system. The effective pyrolysis can provide a high heat transfer rate and short resident time, which can generate high yield of liquid product and prevent the second cracking of the liquid 
product. Considerable attention has been given to the development of pyrolysis reactors during recent decades, which has resulted in several efficient reactors such as the fluid reactor, rotating cone, and ablative reactor. However, the associated systems, such as the feeder system and condenser system, have not keep pace with the development of the reactors and cannot match the pyrolysis reactor for long-term operation due to the clogging problem from the formation of tar. Future work should focus on the comprehensive understanding of the reaction mechanism during the pyrolysis reaction and the interactions between the pyrolytic media, in order to generate an improved understanding and provide a feasible solution for the stability of scaled up facilities.

\subsubsection{Hydrogenation upgrading}

Bio-oil is not produced under conditions of thermodynamic equilibrium, but rather involves a short reactor time at a high pyrolysis temperature followed by a rapid cooling or quenching. This produces a condensate that is also not at thermodynamic equilibrium at storage temperatures. The chemical composition of the bio-oil tends to change toward thermodynamic equilibrium. This is the main reason why upgrading processes for bio-oil production are needed to improve stability and fuel properties. Hydrodeoxygenation (HDO) was an effective upgrading method to remove oxygen in original bio-oil ${ }^{[26]}$ and usually takes place at moderate temperature $\left(300-600^{\circ} \mathrm{C}\right)$ with the presence of catalysts and hydrogen. The oxygen is removed in the form of water.

The HDO process involves saturation of unsaturated components from different components of biomass. That is to say, pyrolytic products generated from cellulose have a specific reaction pathway to form high grade biofuels (mainly short chain alkanes and alkenes), while the phenolics from lignin tend form cycloalkane-rich fuels.

Phenolics can be converted to cycloalkanes and alkenes using various noble metals (Pt, $\mathrm{Rh}, \mathrm{Pd}$ and $\mathrm{Ru}$ ) and nonprecious metal catalysts such as $\mathrm{Ni}$ and/or $\mathrm{Cu}$ supported on $\mathrm{CeO}_{2}-\mathrm{ZrO}_{2}$ and $\gamma-\mathrm{Al}_{2} \mathrm{O}_{3}{ }^{[27-30]}$. Phenol is one of the suitable compounds used to explore the reaction pathways and important intermediates in order to understand the reaction mechanism during the HDO process. According to the literature ${ }^{[29,30]}$, there are two main pathways (Fig. 5) for the HDO process of phenol: (1) hydrogenationhydrogenolysis: hydrogenation of the aromatic ring followed by dehydration forming a $\mathrm{C}=\mathrm{C}$ bond and rehydrogenation of the double bond to cyclohexane, and (2) hydrogenolysis-hydrogenation involving direct hydrogenolysis of $\mathrm{C}-\mathrm{O}$ bonds, followed by hydrogenation of the benzene ring to cylohexane.

Usually, phenolics from pyrolytic products contain methoxy group in their molecular structures. The methoxy group mainly undergoes two reaction routes: (1) demethylation to produce catechol, which is subsequently deoxygenated to phenol, and (2) demethoxylation to produce phenol directly ${ }^{[26-28]}$. After the conversion of the methoxy group to a hydroxyl group, the phenol is then further converted to cycloalkanes.

Carbohydrates (e.g., sugars) usually are first dehydrated to form 5-hydroxymethylfurfural, followed by hydrogenation to 5-(hydroxymethyl)tetrahydrofuran-2-carbaldehyde (Fig. 6, Formula 1). These two reactant units undergo aldol condensation reactions to form large molecules, followed by multi-step hydrogenation/dehydration processes to form C9-C15 alkanes ${ }^{[31]}$.

The furfural intermediate can be processed in a fixed bed reactor by the $\mathrm{HDO}$ process by a catalyst of $\mathrm{Cu}, \mathrm{Pd} /$ $\mathrm{SiO}_{2}{ }^{[32-34]}$. Decarbonylation to furan is the dominant reaction, and furan is further hydrogenated to THF (tetrahydrofuran). Also furan can be converted to butanone and butanol by a ring-opening reaction followed by hydrogenation reaction (Fig. 6, Formula 2).

Aqueous-phase HDO of carboxylic acids over noble mental catalysts was investigated at $300^{\circ} \mathrm{C}$ under the pressure of $6.4 \mathrm{MPa}^{[35]}$. Propanoic acid was converted by $\mathrm{C}-\mathrm{O}$ bond cleavage into aldehyde, followed by hydrogenation to propanol or dehydration-hydrogenation to propane, or the alcohols reacted with carboxylic acids to form esters (Fig. 6, Formula 3).

Aldehydes usually undergo two reactions during the

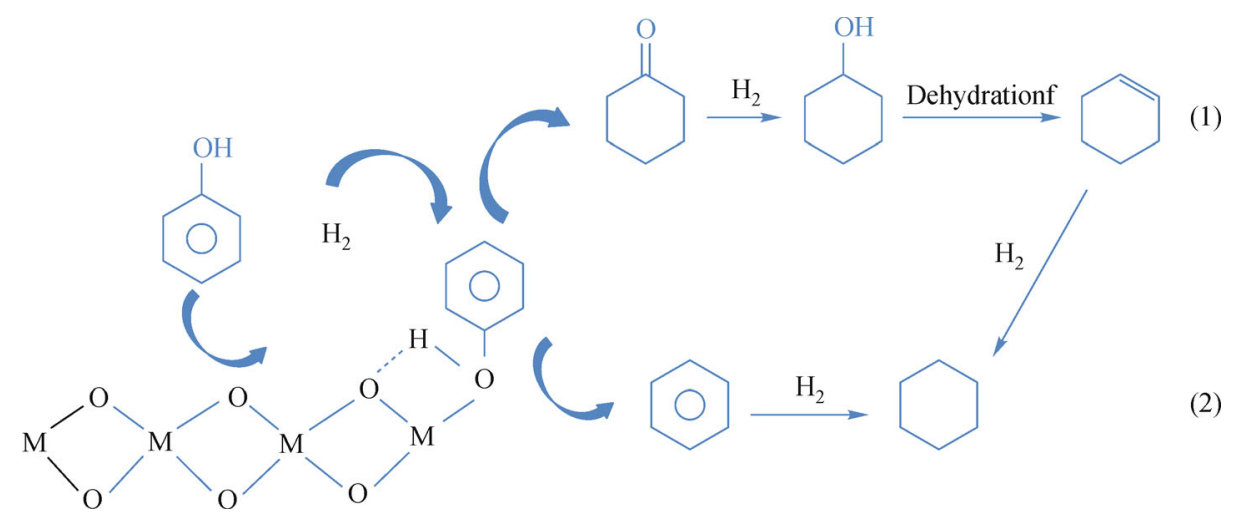

Fig. 5 Proposed mechanism of phenolics hydrodeoxygenation into cyclohydrocarbons (phenol as model compound) 


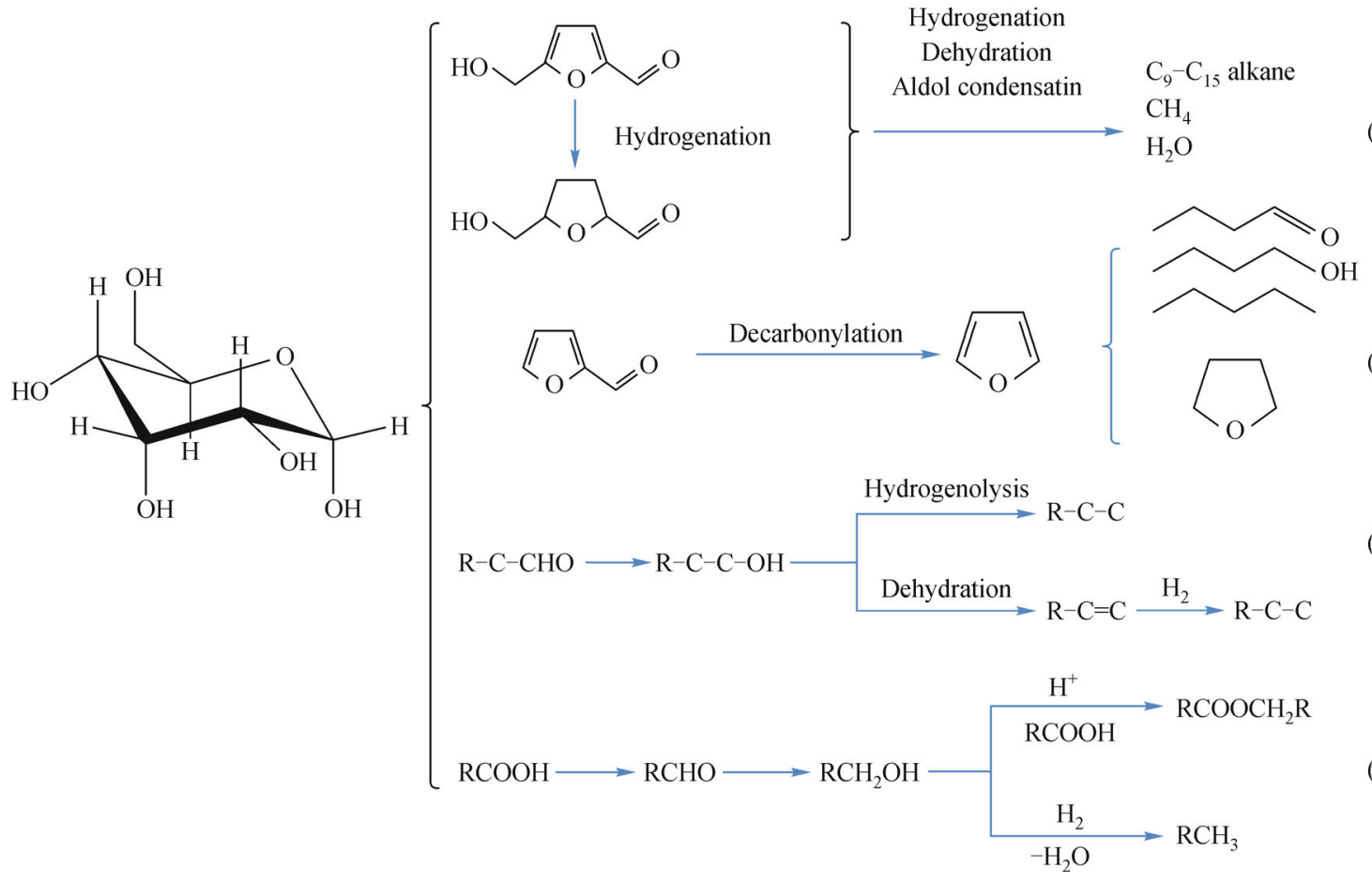

Fig. 6 Hydrodeoxygenation (HDO) process for the reaction pathway producing pyrolytic products from cellulose

HDO process. Both of them take place after hydrogenation of $\mathrm{C}=\mathrm{O}$ bonds to form alcohols. The alcohols could be converted to alkanes directly by hydrogenolysis of $\mathrm{C}-\mathrm{O}$ bonds, or by dehydration to produce olefins and subsequently $\mathrm{C}=\mathrm{C}$ bond rehydrogenation to form corresponding alkanes (Fig. 6, Formula 4) ${ }^{[36]}$.

After the HDO process, the products are oxygen-free and of high quality, as shown in Table 3, and they can be blended with petroleum-based fuels. All the fuel properties are significantly improved after the HDO process. A large proportion of the HDO bio-oil can be distilled to obtain purified fuels, which indicates the thermal stability of the bio-oil is improved by the removal of oxygen. Based on the analysis of HDO reactions and molecular structures, removal of oxygen leads to the rearrangement of molecular structures, the hydrocarbons formed during the HDO process have good chemical stability compared to the oxygenated compounds in earlier bio-oils.

\subsubsection{Catalytic cracking}

Bio-oils can be upgraded using catalytic cracking to reduce their oxygen content and improve their thermal stability. The advantages of catalytic cracking are that no $\mathrm{H}_{2}$ is required, atmospheric pressure processing reduces operating costs, and the temperatures employed are similar to those used in the production of bio-oil ${ }^{[38]}$. This offers significant processing and economic advantages over the HDO process. However, poor yields of hydrocarbons and high yields of coke may occur with biomass-derived feedstocks. These results can be improved by operating at the proper conditions with the appropriate catalyst. The products from catalytic cracking of biomass-derived molecules include hydrocarbons (aromatic and aliphatic), water-soluble organics, water, oil-soluble organics, gases $\left(\mathrm{CO}_{2}, \mathrm{CO}\right.$ and light alkanes) and coke.

A typical reaction system for catalytic cracking of biooil is shown in Fig. 7. The original bio-oil was introduced into the reactor accompanied by the carrier gas (usually $\mathrm{N}_{2}$ ) by metering pump through a preheater. The bio-oil vapor then pass through a packed column loaded with catalyst in the catalytic cracking reactor at temperatures ranging from 300 to $500^{\circ} \mathrm{C}$. After the cracking reaction, the upgraded bio-oil and non-condensed gas were separated in a steel separator.

The most frequently used catalysts in catalytic cracking processes are molecular sieves, such as ZSM-5 (Zeolite Socony Mobil-5). A molecular sieve is a material with very small holes of precise and uniform dimensions. These holes are small enough to block large molecules while allowing small molecules to pass. The basic structure of molecular sieves are crystalline metal aluminosilicates having a three dimensional interconnecting network of silica and alumina tetrahedra. The absence of alumina in molecular sieves can provide acidic sites during the cracking reaction, which leads to the structural rearrangement of the reactants.

Molecular sieves are often utilized in the petroleum 
Table 3 Properties of pyrolysis oil and hydrodeoxygenation (HDO) bio-oil ${ }^{[37]}$

\begin{tabular}{lcc}
\hline Property & Fast pyrolysis & HDO bio-oil \\
\hline Carbon/\% & 43.5 & $85.3-89.2$ \\
Hydrogen/\% & 7.3 & $10.5-14.1$ \\
Oxygen/\% & 49.2 & $0.0-0.7$ \\
H/C-ratio (dry) & 1.23 & $1.40-1.97$ \\
Density/(g- $\mathrm{mL}^{-1}$ ) & 24.8 & $0.796-0.926$ \\
Moisture/\% & 24.8 & $0.001-0.008$ \\
Higher heating value $\left(\mathrm{MJ} \cdot \mathrm{kg}^{-1}\right)$ & 22.6 & $42.3-45.3$ \\
Viscosity/cP & $59\left(40^{\circ} \mathrm{C}\right)$ & $1.0-4-6\left(23^{\circ} \mathrm{C}\right)$ \\
Aromatic/Aliphatic carbon & - & $38 / 62-22 / 78$ \\
Research octane number & - & 77 \\
Distillation range $/ \%$ & & $97-36$ \\
$\quad$ Initial boiling point $-225^{\circ} \mathrm{C}$ & 44 & $0-41$ \\
$\quad 225-350^{\circ} \mathrm{C}$ & coked & \\
\hline
\end{tabular}

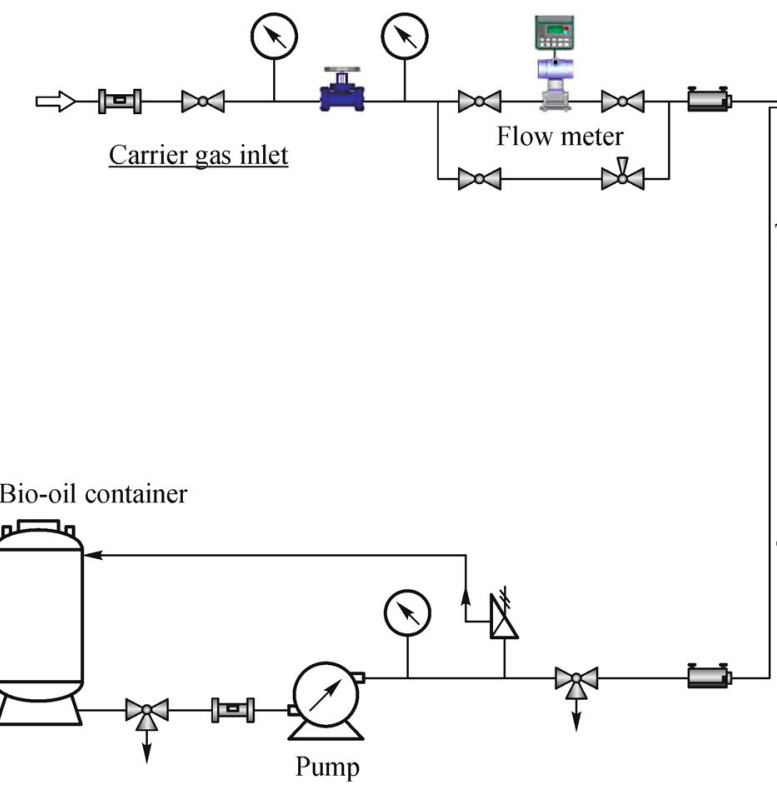

Preheater

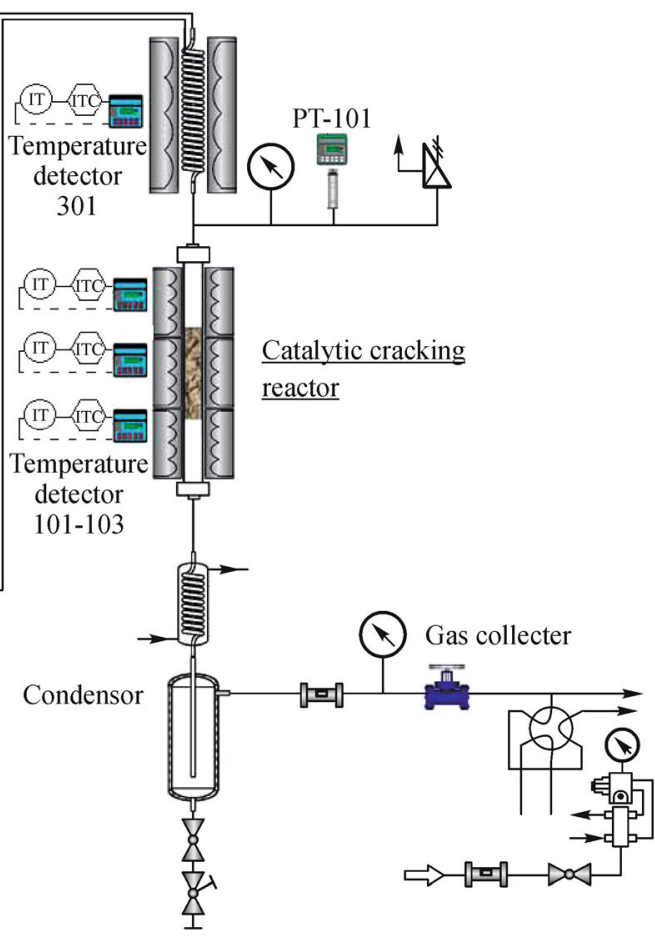

Upgraded bio-oil

Fig. 7 A typical catalytic cracking system

industry, especially for shape selective reaction of long chain hydrocarbons to aromatics. Therefore, these molecular sieves can also be employed to upgrade the pyrolytic vapors from the biomass to achieve a molecular structure rearrangement ${ }^{[39-41]}$. Different biomass-derived bio-oils, with a range of different functionalities, could be converted to aromatic hydrocarbons and olefins over a ZSM-5 catalyst (Fig. 8).

Recent studies regarding the catalytic cracking reactions focus on the development of different types of molecular 

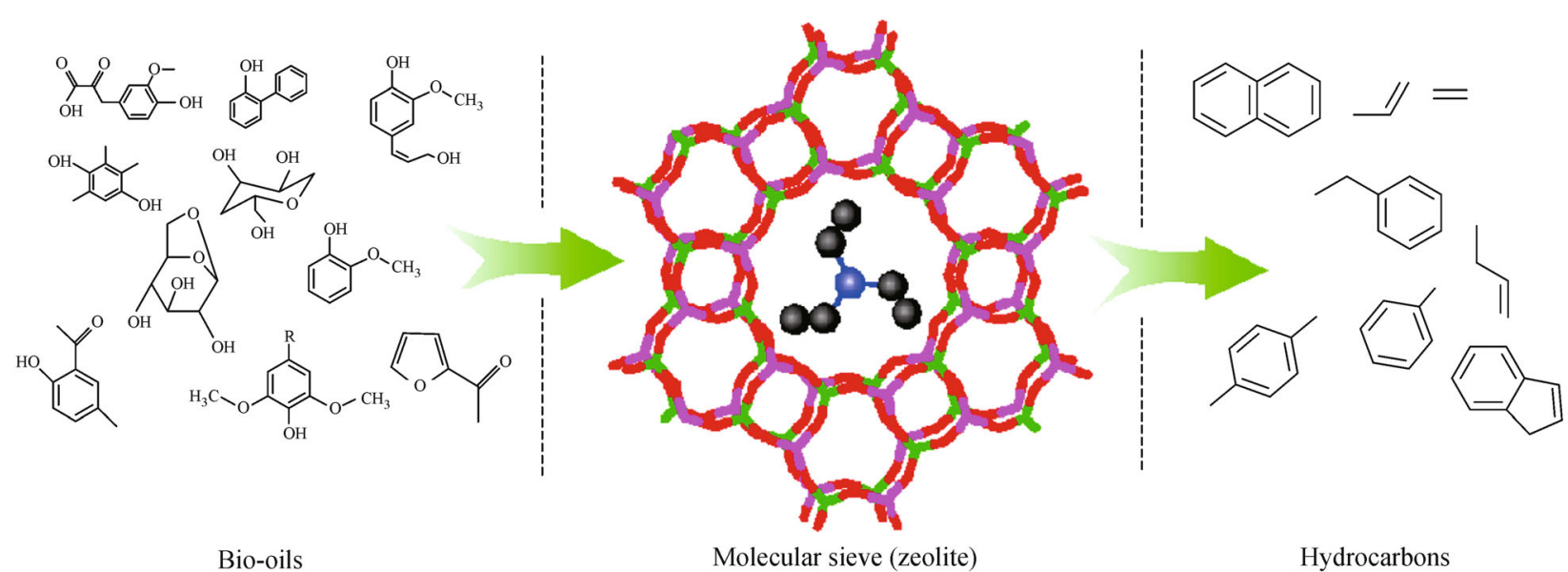

Shape selective reaction

Fig. 8 Reaction pathway of bio-oil during the catalytic cracking reaction

sieve catalysts. Catalysts with different pore widths and pore structures have been tested and compared in recent decades.

The catalytic upgrading of pyrolytic oils is achieved over Hydro Zeolite Sieve of Molecular porosity-5 (HZSM5 ), and the upgraded oil may be easily separated from the aqueous phase ${ }^{[42]}$. A higher yields of oil $(45 \%-50 \%)$ was obtained at $450^{\circ} \mathrm{C}$ with HZSM-5/50. The catalytic upgrading produced highly deoxygenated oil having a quite elevated heating value and a good combustibility. The formation of coke on the catalyst was not negligible and hence may be the cause of a rapid deactivation.

Hyun Ju Park ${ }^{[43]}$ provided catalytic upgrading of bio-oil using Ga modified ZSM-5 for the pyrolysis of sawdust in a bubbling fluidized bed reactor. The maximum yield of oil products was found to be about $60 \%$. The yield of gas was increased as was catalyst added. HZSM-5 showed a larger gas yield than $\mathrm{Ga} / \mathrm{HZSM}-5$. When bio-oil was upgraded with HZSM-5 or Ga/HZSM-5, the amounts of aromatics in the products increased. Analysis of product yields over $\mathrm{Ga} /$ HZSM-5 showed higher amounts of aromatic components, such as benzene, toluene and xylene, than HZSM-5.

Using a strongly acidic catalyst such as HZSM-5, it was found that the catalyst used in the cracking process was deactivated quickly. By analyzing the catalyst ${ }^{[44]}$, it was assessed that the loss of activity is likely connected to the disappearance of a significant amount of acidic sites, mainly the stronger ones, due to the thermal cycling to which the catalyst was submitted. The regeneration of catalyst was conducted at $500^{\circ} \mathrm{C}$, usually raising the temperature above $500^{\circ} \mathrm{C}$ due to the combustion of coke. The repeated regeneration treatments, however, gradually preferentially deactivated the acid sites.

The reason why ZSM-5 catalysts easily coked during catalytic cracking is that the ZSM-5 catalyst has a specific pore size structure with an elliptical pore of 5.4-5.6 $\AA$ in diameter that is shape-selective. The particular pore size structure allows compounds of the approximate molecular size of a C10 molecule to enter and leave the structure. Therefore, the high molecular weight compounds in bio-oil tend to form coke on the surface of the catalyst.

To solve these issues, mesoporous (pore diameter, 2$3 \mathrm{~nm}$ ) materials with larger pores, such as Mobil Composition of Matter No. 41 (MCM-41) molecular sieves, were used in the cracking process in order to avoid condensation of the pyrolysis products. The large mesoporous structure could also ensure that the volatiles formed pass through the catalyst for upgrading of the bio-oil before undergoing secondary reactions. The yield of liquid product is usually higher than when using the microporous materials (ZSM-5).

Adam $^{[45]}$ used four Al-MCM-41 type catalysts with a Si/ Al ratio of 20 in catalytic cracking of bark-free spruce wood. Levoglucosan disappeared and the yields of heavier components decreased significantly under the effect of the catalysts. The overall yield of pyrolysis vapors decreased as well. The effects of MCM-41 type catalyst seem to be related to the size of the pores of the catalyst. Pore size enlargement and transition metal incorporation reduces the yield of acetic acid and water among pyrolysis products.

Adam $^{[46]}$ used Al-MCM-41 and SBA-15 in catalytic processes and compared these to non-catalytic experiments. In the catalytic experiments, the hydrocarbon and acid yields increased while the carbonyl and the acid yields decreased and it was concluded that Al-MCM-41 was the catalyst with the higher performance.

\subsection{Solvent liquefaction of lignocellulosic biomass}

\subsubsection{Current Liquefaction process}

Biomass liquefaction is a decomposition process of 
lignocellulosic materials in organic/aqueous solutions under pressure. Many solvents have been used as effective reaction media during liquefaction, including water, alcohol, phenol and multiple hydroxyl compounds (PEG, ethylene glycol, and glycerol). The liquid product obtained has better fuel properties with high conversion rates compared with the bio-oil from fast pyrolysis reaction, i.e., low moisture, higher heat value and acids free.

Reports from the past 5 years about liquefaction reactions in solvents are listed in Table 4. It seems that only those products liquefied in water/low carbon alcohols are proposed as suitable for biofuel production ${ }^{[4-49]}$. Products of liquefaction in phenol and glycerol are mainly used as substitute materials, such as phenolic resins and polyurethane foams ${ }^{[50,51]}$.

As shown in Table 4, most of the catalysts used in liquefaction are acidic and basic. It was found that acidic catalyst can significantly improve the conversion of cellulosic biomass, by up to $90 \%$ according to the majority of reports. However, the corrosive nature of the catalyst is a big barrier for industry applications. Basic catalysts, such as $\mathrm{NaOH}$ and $\mathrm{Ca}(\mathrm{OH})_{2}$, employed during the liquefaction avoid the corrosion of steel containers. However, the conversion of the biomass is low, usually below $40 \%$.
Water is the cheapest solvent used in liquefaction. However, yields of the product usually are not satisfactory and several reports indicate that only $5 \%-40 \%$ of biomass conversion is achieved. Also, there is the need for treatment of water soluble compounds in order to avoid the deleterious environmental impact. Low-carbon alcohol is a potential solvent for liquefaction. These alcohols not only can improve the yield, but also can be easily recovered by distillation after the reaction.

Although the properties of liquefied oils are improved to a certain extent compared with fast pyrolysis oil, the properties are still not equivalent to those of petroleum fuels. Additional upgrading processes, such as hydroprocessing, are needed, which yields a product very similar to the bio-oil generated from fast pyrolysis reaction ${ }^{[52]}$.

Researchers at the Pacific North-west National Laboratory studied hydrogenation of bio-oil produced from high pressure liquefaction of wood $^{[53,54]}$. Hydroprocessing studies were conducted using a continuous-flow fixedbed catalyst system using an up-flow configuration. Compared to the light oil fraction, the complete oil required more severe operating conditions, such as a higher residence time (lower space velocity) and operating pressure.

Table 4 Recent studies on liquefaction of biomass in solvents for biofuel production

\begin{tabular}{|c|c|c|c|c|c|c|}
\hline Raw materials & Solvent & Catalyst & Conditions & Yield/\% & Purpose & Reference \\
\hline Algal biomass & Water & - & $\begin{array}{c}300^{\circ} \mathrm{C}, 10-12 \mathrm{MPa}, \text { and } 30 \\
\text { min retention time }\end{array}$ & $24-45$ & Liquid fuel & {$[57]$} \\
\hline Microalgae & Water & - & $350^{\circ} \mathrm{C}$ for $60 \mathrm{~min}$ & 40 & Liquid fuel & {$[58]$} \\
\hline Microalgae & Water & $\mathrm{Na}_{2} \mathrm{CO}_{3} /$ Formic acid & $350^{\circ} \mathrm{C}, \sim 200 \mathrm{bar}$ & $5-25$ & Liquid fuel & {$[59]$} \\
\hline \multirow[t]{2}{*}{ Kenaf biomass } & $\begin{array}{l}1 \text { st step: water } \\
2 \text { nd step: tetralin }\end{array}$ & $\begin{array}{c}\text { Activated carbon supported } \\
\text { Ru catalyst }\end{array}$ & $\begin{array}{c}1 \text { st step: } 250^{\circ} \mathrm{C}, 2 \mathrm{~h} \\
2 \text { nd step: } 350^{\circ} \mathrm{C} \\
5 \mathrm{MPa} \mathrm{H}_{2}\end{array}$ & 2 nd step: $70-75$ & Liquid fuel & {$[60]$} \\
\hline & Water & $\begin{array}{c}1 \text { st step: Acid } \\
2 \text { nd step: } \mathrm{Ca}(\mathrm{OH})_{2}\end{array}$ & $\begin{array}{l}1 \text { st: } 200^{\circ} \mathrm{C} \\
2 \text { nd: } 380^{\circ} \mathrm{C}\end{array}$ & 40 & Liquid fuel & {$[61]$} \\
\hline $\begin{array}{l}\text { Pine (Pinus sp.) } \\
\text { wood }\end{array}$ & Ethanol & No catalyst & $\begin{array}{l}(0-240 \mathrm{~min}),\left(280-400^{\circ} \mathrm{C}\right) \\
\mathrm{N}_{2} \text { pressure }(0.4-7.5 \mathrm{MPa})\end{array}$ & $15.8-59.9$ & Liquid fuel & {$[62]$} \\
\hline \multirow[t]{2}{*}{$\begin{array}{l}\text { Bio-ethanol } \\
\text { residue (grains) }\end{array}$} & Ethanol & $\begin{array}{c}\left(\mathrm{K}_{2} \mathrm{CO}_{3}\right) / \text { Zirconia-based } \\
\text { catalyst }\end{array}$ & $280-370^{\circ} \mathrm{C}, 25 \mathrm{MPa}$ & 34 & Liquid fuel & {$[63]$} \\
\hline & $\begin{array}{c}\text { Co-solvent: alcohol and } \\
\text { water }\end{array}$ & - & $300^{\circ} \mathrm{C}$ for $15 \mathrm{~min}$ & $\sim 65$ & Liquid fuel & {$[64]$} \\
\hline Sawdust & Glycol/Ethanol & $\mathrm{H}_{2} \mathrm{SO}_{4}$ & $250^{\circ} \mathrm{C}, 1 \mathrm{~h}$ & 97.8 & Liquid fuel & [65] \\
\hline $\begin{array}{l}\text { Pine (Pinus sp.) tree } \\
\text { sawdust }\end{array}$ & $\begin{array}{c}\text { Co-solvent: methanol and } \\
\text { water }\end{array}$ & $\mathrm{H}_{2} \mathrm{SO}_{4}$ & $\begin{array}{c}5 \mathrm{~min} \text { to } 180^{\circ} \mathrm{C} \text {, keep at } \\
180^{\circ} \mathrm{C} \text { for } 15 \mathrm{~min}\end{array}$ & $48.5-76.3$ & & {$[66]$} \\
\hline Corn stover & glycerol & $\begin{array}{l}1 \text { st step: } \mathrm{H}_{2} \mathrm{SO}_{4} \\
2 \text { nd step: } \mathrm{NaOH}\end{array}$ & $\begin{array}{c}1 \text { st step: } 150^{\circ} \mathrm{C} \text { for } 30- \\
165 \mathrm{~min} \\
2 \text { nd step: } 240^{\circ} \mathrm{C} \text { for } 45- \\
180 \mathrm{~min}\end{array}$ & - & Polyols & {$[67]$} \\
\hline Corn stover & Glycerol & $\mathrm{NaOH}$ & $240^{\circ} \mathrm{C}$ for $3 \mathrm{~h}$ & - & Polyols & {$[68]$} \\
\hline Rapeseed cake & Polyethylene glycol & $\mathrm{H}_{2} \mathrm{SO}_{4}$ & $140-180^{\circ} \mathrm{C}, 1 \mathrm{~h}$ & $70-88$ & Polyols & [69] \\
\hline Sawdust, cornstalk & Hot-compressed water & - & $250-350^{\circ} \mathrm{C}, 2 \mathrm{MPa} \mathrm{H}_{2}$ & 32 & Phenolics & [70] \\
\hline Japanese beech & Phenol & - & $350^{\circ} \mathrm{C}, 4.2 \mathrm{MPa}, 30 \mathrm{~min}$ & 99.1 & Phenolics & [71] \\
\hline
\end{tabular}


Most of the catalysts used in this process are transition metals. A study involving screening of different hydrotreatment catalysts revealed that there were no dramatic differences between the performances within the same family of catalysts ${ }^{[52]}$. Copper-based catalysts usually provided low activity. Nickel-based catalysts produced more gaseous products, consumed more hydrogen and were less durable. The sulfide form of the Co-Mo hydrotreating catalyst considerably outperformed the oxide form of the same catalyst. This implies that if a hydrotreatment catalyst is used for completing the hydrogenation of liquefied oil, it should remain in a sulfide form (using an appropriate source of $\mathrm{H}_{2} \mathrm{~S}$ ) during the biooil upgrading process.

The effect of hydrotreatment catalyst pore size on the upgrading of liquefied biomass has been investigated ${ }^{[55]}$. Three catalysts were used, two catalysts with large average pore diameters and one catalyst with much smaller pore diameter. Although the smaller pore-size catalyst showed the best hydrogenation performance, it was unable to maintain its pore size during the course of the run. Since the two catalysts with larger pore diameters were able to maintain their pore volumes better, it is speculated that the larger pore diameter catalysts would show a better longterm performance compared to the narrow pore catalyst due to higher stability.

A promising dual hydrotreatment catalyst system was developed for concurrently decreasing the oxygen content and cracking reactions. Baker et al. ${ }^{[56]}$ proposed a two-step process modification to increase the aromatic gasoline yields while minimizing hydrogen consumption. This process involved separation of the lighter components from the products obtained after the hydrotreatment step and feeding only the heavier components to the hydrocracking section. According to the authors the proposed modification maximized aromatic gasoline production by avoiding the unnecessary saturation/loss of aromatic compounds (over the hydrocracking catalyst) of the gasoline fraction produced in the hydrotreatment step.

\subsubsection{Integrated liquefaction}

Liquefaction of biomass can produce phenolic compounds. At the same time, biomass can produce monosaccharide derivatives. The reason for this is that biomass is made up of three main components: cellulose, hemicellulose and lignin. There are significant differences between the decomposition products from lignin and those from cellulose and hemicellulose.

The liquefied products from cellulose and hemicellulose provide sufficient hydroxyl functionalities because original units of the components have plenty of hydrophilic groups, such as hydroxyl groups and carbonyl groups. In contrast, decomposition products of the lignin usually consist of phenol derivatives. So far, there is no efficient method to separate these two groups of liquefied products. There are hundreds of oxygenated compounds in liquefied products, which increases the cost of the separation methods (such as distillation and extraction) and lowers yields, increasing the importance of co-product utilization or disposal.

An integrated liquefaction of biomass proposed by the Chinese Academy of Forestry might be an alternative solution to the separation of phenolics and sugar derivatives from liquefied products ${ }^{[72]}$. By liquefaction of biomass using microwave energy with acidic catalyst, only two groups of liquefied products, sugar derivatives and phenolic compounds, were obtained with similar molecular structures. A convenient fractionation method for sugar derivatives and phenolic compounds according to their hydrophilic/hydrophobic properties was proposed, with a purity of $80 \%$ and $65 \%$ for sugar derivatives and phenolic, respectively. Figure 9 show a processing scheme in which the focus is on the integrated use of the three major components in biomass. The major purpose is to produce two kinds of products according to their original molecular structure.

This strategy means that cellulose and lignin derivatives liquefied from biomass could be fractionated conveniently according to their hydrophilic and hydrophobic properties. This simple approach can achieve an integrated use of liquefied products toward different synthesis directions based on their molecular structures.

A scaled up reactor system with the capacity of $500 \mathrm{t}$ per year has been built in 2014 by the Chinese Academy of Forestry (Fig. 10). A conversion of $85 \%$ can be reached on the basis of $200 \mathrm{~kg}$ dry biomass. As evidenced by Gas chromatograph-Mass spectrometer analysis, the biopolyols contained methyl sugar derivatives, including methyl $\beta$-Dmannofuranoside, methyl $\alpha$-D-galactopyranoside, methyl $\alpha$-D-glucopyranoside and methyl $\beta$-D-glucopyranoside. Total sugar content was up to $75 \%$. The phenolic products separated from the liquefied product were mainly composed of phenolic derivatives such as 2-methoxy-4-propylphenol and 4-hydroxy-3-methoxy-benzoic acid methyl ester, with a content of $65 \%$. This result showed good agreement with previous research ${ }^{[72]}$.

\section{Future directions}

Biomass is the only renewable source of carbon, which could generate liquid fuels through direct thermochemical conversion. Liquid biofuels, especially second generation biofuels, will be important for the development of human society in the near future due to the fact that fossil fuels continue to be depleted. Production of liquid fuels by thermochemical conversion on a commercial scale depends on the availability of feedstock, a suitable catalysis system and catalytic reactors. Although useful information has been provided by research, two important barriers remain. 

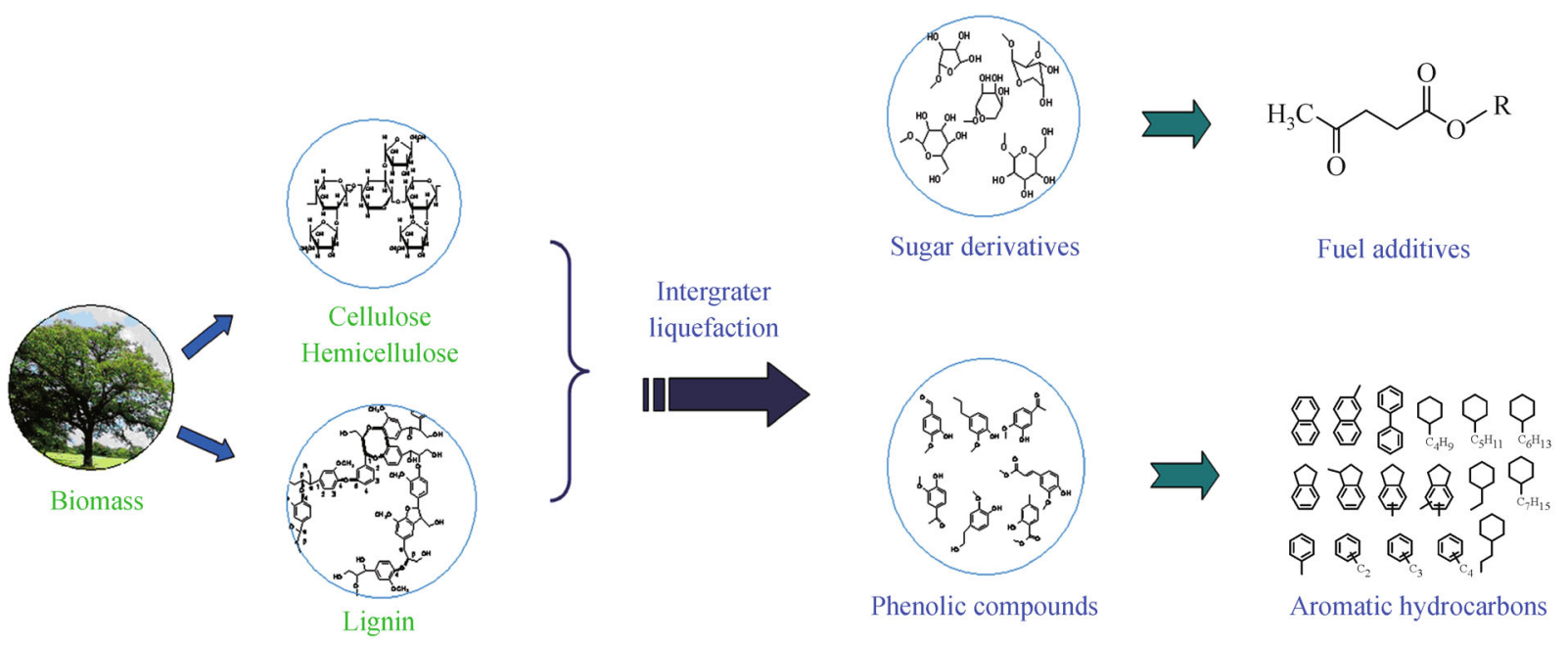

Fig. 9 Production of biopolyols and phenolic compounds from liquefied products of biomass

(a)

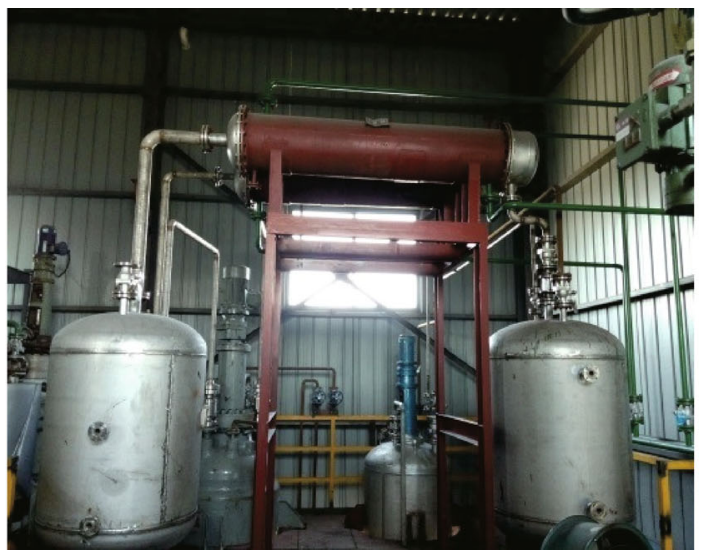

(b)

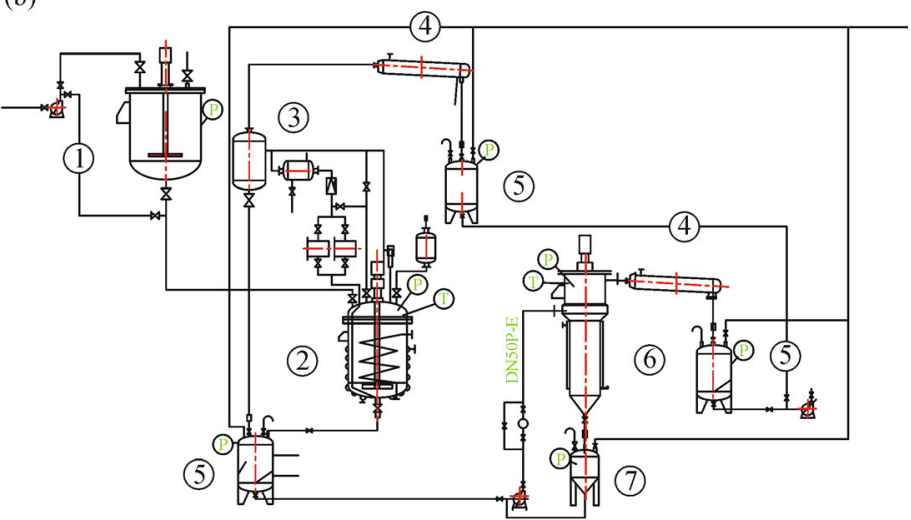

Fig. 10 Integrated liquefaction system developed by the Chinese Academy of Forestry. (a) Stereogram; (b) schematic diagram: (1) material container; (2) high pressure reactor; (3) filter system; (4) condenser; (5) alcohol tanks; (6) film evaporator; (7) product collector.

Thermochemical conversion of lignocellulosic biomass still presents a technological barrier, not only in laboratory scale research, but also in scaled up processes. This barrier is mainly caused by the complex nature of the cellulose and lignin in the biomass, which leads to unpredictable reaction pathways during thermochemical conversion. This is why studies of thermochemical conversion mechanisms are still in an initial stage. For a long time, the deoxygeneration of the biomass feedstock was the explanation for improving the quality of the pyrolytic oils, but this resembles a blackbox reaction. We do not understand the exact reaction pathways during the conversion, which generate a large amount of undesirable product that are detrimental to the fuel properties of pyrolytic oils.

Lack of the clarity about the mechanisms also creates a technology barrier to the scale up facilities for fast pyrolysis of lignocellulosic biomass. The feeder system and the condenser system are often clogged by the formation of tar, and could not match the pyrolysis reactor for long-term operation. Comprehensive understanding of the reaction mechanisms might disclose the reason and provide a feasible solution for designing stablescaled up facilities.

There are two main methods to meet this challenge. The first is developing a highly efficient catalyst and reaction system which could lead to the multiple reactions from different kinds of reactive groups in liquefied biomass, such as carboxylic group, aldehydes and ketones, producing molecular structures with the desired fuel properties, such as esters, alkanes and alkenes. This methodology is 
currently being studied by many researchers, including catalytic cracking and hydrodeoxygeneration. Reduction in the cost of the catalyst in terms of their activity, selectivity and development of micro/mesoporous composite catalysts, and silica alumina composite catalysts with stability and long life are needed due to the poor quality of the bio-oils (high oxygen content, impurity levels, molecular complexity and coking propensity).

An alternative solution is to produce predictable products during a liquefaction process. So far, there is no efficient method to track the reactions during the conversion. Although studies of mechanisms have been proposed using model compounds, such as glucose, phenol and acetic acid, the reactions that actually occur during biomass liquefaction are much more complicated, including the inter-reactions of the intermediates, and transformations of second cracking products. Therefore, directional liquefaction might be an approach for production of high grade liquid biofuels.

The basic concept of directional liquefaction is simple. It is the generation of different classes of chemicals from biomass with similar molecular structure, such as sugars (basic union of cellulose and hemicellulose) and phenolics (structural unit of lignin). This processing can simplify the upgrading process because the similar molecular structure represent similar physical and chemical properties. These chemicals can be catalyzed for preparation of liquid biofuels and prevention of most side reactions due to their similar properties. For example, sugar derivatives could be converted to levulinate esters (a high grade fuel additive) through an important chemical intermediate (5-hydroxymethylfurfural). Phenolics could be converted into aromatic hydrocarbons through in situ hydrogenation catalyzed by noble metals. This proposal indicates that similar chemicals could be upgraded to specific molecular structure with good fuel properties by reaction route design.

There are two ways to realize directional liquefaction. The first is separation of lignin and cellulose from the biomass before the thermochemical conversion. Then, the separated cellulose and lignin undergo thermochemical conversion independently. Different types of products are decomposed from cellulose with hydrophilic molecules which have hydroxyl groups, carbonyl groups and aldehydes, and lignin generates phenolic compounds. The second approach is fractionation of liquefied biomass after thermochemical conversion, which will need a highly selective catalyst and reaction system to generate similar molecules and prevent these molecules from further decomposition.

It is worth noting that the first method for directional liquefaction could be integrated with the existing facilities present in paper and pulp engineering. It is well known that the separation of lignin from cellulose is commercially available in the paper making industry. The products from directional liquefaction, with similar properties, have great potential for synthesis of high value products, such as levulinate esters and 2,5-dimethylfuran (high grade biofuels). Integrating biofuel production processes with the paper making industry is required to reduce operating cost, and to eventually increase the biofuel value to make it economically viable. From a technical viewpoint, extensive research on the nature of feedstocks and catalyst systems as well as reactor technology is also needed.

\section{Conclusions}

Lignocellulosic biomass is the main feedstock for the production of second generation biofuels. The processing of biomass-based feedstock by thermochemical conversion is a promising alternative for the future of biofuel production. So far, the thermochemical conversion of lignocellulosic biomass has been demonstrated for bio-oil production around the world. However, this process still has technological barriers not only in the laboratory-scale research, but also in scaled up facilities. Directional liquefaction of biomass to generate groups of intermediates with similar chemical properties might be an alternative solution. Therefore, future work should focus on understanding the reaction pathways for using different types of lignocellulosic feedstock, with the ultimate goal of designing new and improved catalysts that display higher selectivity. Although there are several uncertainties associated with renewable liquid fuels, one thing is certain, the economic and environmental importance coupled with the enormous challenges will continue to maintain this as one of the most vibrant areas of research.

Acknowledgements The authors would like to thank the National Natural Science Foundation of China (31422013) and the Research Institute of New Technology, Special Fund for Fundamental Research (CAFYBB2014ZD003) for financial support during this investigation.

Compliance with ethics guidelines Jianchun Jiang, Junming $\mathrm{Xu}$ and Zhanqian Song declare that they have no conflict of interest or financial conflicts to disclose.

This article is a review and does not contain any studies with human or animal subjects performed by any of the authors.

\section{References}

1. IEA. Key world energy statistics. The International Energy Agency, 2013

2. Gerland P, Raftery A E, Sevčíková H, Li N, Gu D, Spoorenberg T, Alkema L, Fosdick B K, Chunn J, Lalic N, Bay G, Buettner T, Heilig G K, Wilmoth J. World population stabilization unlikely this century. Science, 2014, 346(6206): 234-237

3. van Ruijven B, van Vuuren D P. Future bio-energy potential under various natural constraints. Energy Policy, 2009, 37(11): 47974808

4. Balat M. Production of bioethanol from lignocellulosic materials via the biochemical pathway: a review. Energy Conversion and Management, 2011, 52(2): 858-875 
5. Sorrell S, Speirs J, Bentley R, Brandt A, Miller R. Global oil depletion: a review of the evidence. Energy Policy, 2010, 38(9): 5290-5295

6. Mortensen P M, Grunwaldt J D, Jensen P A, Knudsen K G, Jensen A D. A review of catalytic upgrading of bio-oil to engine fuels. Applied Catalysis A: General, 2011, 407(1-2): 1-19

7. Renewable Energy Road Map. Available at Europa Website on April 14, 2015

8. Development of Renewable Energy. National Development and Reform Commission, 2007

9. Clean energy Progress Report. The International Energy Agency, 2011

10. Mohan D, Pittman C U Jr, Steele P H. Pyrolysis of wood/biomass for bio-oil: a critical review. Energy \& Fuels, 2006, 20(3): 848-889

11. The EU biodiesel industry. European Biodiesel Board (EBB). Available at EBB Website on April 14, 2015

12. World Ethanol \& Biofuel (WEB). Available at WEB Website on April 14, 2015

13. Zhang Q, Chang J, Wang T, Xu Y. Review of biomass pyrolysis oil properties and upgrading research. Energy Conversion and Management, 2007, 48(1): 87-92

14. Holladay J E, Bozell J J, White J F, Johnson D. Top value-added chemicals from biomass. Volume II-results of screening for potential candidates from biorefinery lignin. U.S. Department of Energy, 2007

15. Junming X, Jianchun J, Wei L, Weidi D, Yunjuan S. Rice husk biooil upgrading by means of phase separation and the production of esters from the water phase, and novolac resins from the insoluble phase. Biomass and Bioenergy, 2010, 34(7): 1059-1063

16. Oasmaa A, Czernik S. Fuel oil quality of biomass pyrolysis oilsstate of the art for the end-users. Energy \& Fuels, 1999, 13(4): 914 921

17. Bridgwater A V. Review of fast pyrolysis of biomass and product upgrading. Biomass and Bioenergy, 2012, 38: 68-94

18. Scott D S, Piskorz J, Radlein D. Liquid products from the continuous flash pyrolysis of biomass. Industrial \& Engineering Chemistry Process Design and Development, 1985, 24(3): 581-588

19. Scott D S, Piskorz J. The flash pyrolysis of aspen poplar wood. Canadian Journal of Chemical Engineering, 1982,60(5): 666-674

20. Cuevas A, Reinoso C, Scott D S. Pyrolysis oil production and its perspectives. In: Proceeding of power production from biomass II. Espoo: VTT, 1995

21. Robson A. PyNe newsletter No. 11. UK: Aston University, 2001, $1-2$

22. Prins W, Wagenaar B M. Review of rotating cone technology for flash pyrolysis of biomass. Kaltschmitt M K, Bridgwater A V, eds. Biomass gasification and pyrolysis. UK: CPL Scientific Ltd., 1997, 316-326

23. Wagenaar B M, Venderbosch R H, Carrasco J, Strenziok R B J, van der A. Rotating cone bio-oil production and applications. Bridgwater A V, eds. Progress in thermochemical biomass conversion, 2001, 1268-1280

24. Peacocke G V C, Bridgwater A V. Ablative plate pyrolysis of biomass for liquids. Biomass and Bioenergy, 1995, 7(1-6): 147-154

25. Bridgwater A V, Peacocke G V C, Robinson N M. Ablative thermolysis reactor. US Patent 7625532, 2003
26. Elliott D C. Historical developments in hydroprocessing bio-oils. Energy \& Fuels, 2007, 21(3): 1792-1815

27. Mortensen P M, Grunwaldt J D, Jensen P A, Jensen A D. Screening of catalysts for hydrodeoxygenation of phenol as a model compound for bio-oil. ACS Catalysis, 2013, 3(8): 1774-1785

28. Zhao C, He J, Lemonidou A A, Li X, Lercher J A. Aqueous-phase hydrodeoxygenation of bio-derived phenols to cycloalkanes. Journal of Catalysis, 2011, 280(1): 8-16

29. Lee C R, Yoon J S, Suh Y W, Choi J W, Ha J M, Suh D J, Park Y K. Catalytic roles of metals and supports on hydrodeoxygenation of lignin monomer guaiacol. Catalysis Communications, 2012, 17: 5458

30. Bykova M V, Ermakov D Y, Kaichev V V, Bulavchenko O A, Saraev A A, Lebedev M Y, Yakovlev V A. Ni-based sol-gel catalysts as promising systems for crude bio-oil upgrading: guaiacol hydrodeoxygenation study. Applied Catalysis B: Environmental, 2012, 113-114: 296-307

31. Huber G W, Chheda J N, Barrett C J, Dumesic J A. Production of liquid alkanes by aqueous-phase processing of biomass-derived carbohydrates. Science, 2005, 308(5727): 1446-1450

32. Sitthisa S, Sooknoi T, Ma Y, Balbuena P B, Resasco D E. Kinetics and mechanism of hydrogenation of furfural on $\mathrm{Cu} / \mathrm{SiO}_{2}$ catalysts. Journal of Catalysis, 2011, 277(1): 1-13

33. Sitthisa S, Resasco D. Hydrodeoxygenation of furfural over supported metal catalysts: a comparative study of $\mathrm{Cu}, \mathrm{Pd}$ and $\mathrm{Ni}$. Catalysis Letters, 2011,141(6): 784-791

34. Sitthisa S, Pham T, Prasomsri T, Sooknoi T, Mallinson R G, Resasco D E. Conversion of furfural and 2-methylpentanal on $\mathrm{Pd} /$ $\mathrm{SiO}_{2}$ and $\mathrm{Pd}-\mathrm{Cu} / \mathrm{SiO}_{2}$ catalysts. Journal of Catalysis, 2011, 280(1): $17-27$

35. Chen L, Zhu Y, Zheng H, Zhang C, Zhang B, Li Y. Aqueous-phase hydrodeoxygenation of carboxylic acids to alcohols or alkanes over supported Ru catalysts. Journal of Molecular Catalysis A: Chemical, 2011, 351: 217-227

36. Dupont C, Lemeur R, Daudin A, Raybaud P. Hydrodeoxygenation pathways catalyzed by $\mathrm{MoS}_{2}$ and NiMoS active phases: a DFT study. Journal of Catalysis, 2011, 279(2): 276-286

37. Huber G W, Iborra S, Corma A. Synthesis of transportation fuels from biomass: chemistry, catalysts, and engineering. Chemical Reviews, 2006, 106(9): 4044-4098

38. Huber G W, Corma A. Synergies between bio- and oil refineries for the production of fuels from biomass. Angewandte Chemie International Edition, 2007, 46(38): 7184-7201

39. Vispute T P, Zhang H, Sanna A, Xiao R, Huber G W. Renewable chemical commodity feedstocks from integrated catalytic processing of pyrolysis oils. Science, 2010, 330(6008): 1222-1227

40. Gayubo A G, Aguayo A T, Atutxa A, Aguado R, Biolbao J. Transformation of oxygenate components of biomass pyrolysis oil on a HZSM-5 zeolite. I. alcohols and phenols. Industrial \& Engineering Chemistry Research, 2004, 43(11): 2610-2618

41. Carlson T R, Vispute T P, Huber G W. Green gasoline by catalytic fast pyrolysis of solid biomass derived compounds. ChemSusChem, 2008, 1(5): 397-400

42. Vitolo S, Seggiani M, Frediani P, Ambrosini G, Politi L. Catalytic upgrading of pyrolytic oils to fuel over different zeolites. Fuel, 1999, 78(10): 1147-1159 
43. Park H J, Park Y K, Kim J S, Jeon J K, Yoo K S, Yim J H, Jung J, Sohn J M, 0. Young-Kwon Park, Joo-Sik Kim. Bio-oil upgrading over Ga modified zeolites in a bubbling fluidized bed reactor. Studies in Surface Science and Catalysis, 2006, 159: 553-556

44. Vitolo S, Bresci B, Seggiani M, Gallo M G. Catalytic upgrading of pyrolytic oils over HZSM-5 zeolite: behaviour of the catalyst when used in repeated upgrading-regenerating cycles. Fuel, 2001, 80(1): $17-26$

45. Adam J, Blazsó M, Me'sza'ros E. Pyrolysis of biomass in the presence of Al-MCM-41 type catalysts. Fuel, 2005, 84: 14941502

46. Adam J, Antonakou E, Lappas A, Stöcker M, Nilsen M H, Bouzga A, Hustad J E, Øye G. In situ catalytic upgrading of biomass derived fast pyrolysis vapours in a fixed bed reactor using mesoporous materials. Microporous and Mesoporous Materials, 2006, 96(1-3): 93-101

47. Hu S, Luo X, Li Y. Polyols and polyurethanes from the liquefaction of lignocellulosic biomass. ChemSusChem, 2014, 7(1): 66-72

48. Effendi A, Gerhauser H, Bridgwater A V. Production of renewable phenolic resins by thermochemical conversion of biomass: a review. Renewable \& Sustainable Energy Reviews, 2008, 12(8): 2092-2116

49. Elliott D C, Biller P, Ross A B, Schmidt A J, Jones S B. Hydrothermal liquefaction of biomass: developments from batch to continuous process. Bioresource Technology, 2014, 178: 147-156

50. Akhtar J, Amin N A S. A review on process conditions for optimum bio-oil yield in hydrothermal liquefaction of biomass. Renewable \& Sustainable Energy Reviews, 2011, 15(3): 1615-1624

51. Toora S S, Rosendahla L, Rudolfb A. Hydrothermal liquefaction of biomass: a review of subcritical water technologies. Energy, 2011, 36(5): 2328-2342

52. Choudhary T V, Phillips C B. Renewable fuels via catalytic hydrodeoxygenation. Applied Catalysis A: General, 2011, 397 (1-2): 1-12

53. Elliott D C. Historical developments in hydroprocessing bio-oils. Energy \& Fuels, 2007, 21(3): 1792-1815

54. Elliott D C, Baker E G. Upgrading biomass liquefaction products through hydrodeoxygenation. Pacific Northwest Laboratory, 1984

55. Gevert S B, Andersson P B W, Sandqvist S P, Jaeraas S G, TokarzM T. Hydroprocessing of directly liquefied biomass with large-pore catalysts. Energy \& Fuels, 1990, 4(1): 78-81

56. Baker E G, Elliott D C. Method of upgrading oils containing hydroxyaromatic hydrocarbon compounds to highly aromatic gasoline. US Patent 5180868, 1993

57. Vardon D R, Sharma B K, Blazina G V, Rajagopalan K, Strathmann $\mathrm{T} J$. Thermochemical conversion of raw and defatted algal biomass via hydrothermal liquefaction and slow pyrolysis. Bioresource Technology, 2012, 109: 178-187

58. Jena U, Vaidyanathan N, Chinnasamy S, Das K C. Evaluation of microalgae cultivation using recovered aqueous co-product from thermochemical liquefaction of algal biomass. Bioresource Technology, 2011, 102(3): 3380-3387

59. Biller P, Ross A B. Potential yields and properties of oil from the hydrothermal liquefaction of microalgae with different biochemical content. Bioresource Technology, 2011, 102(1): 215-225

60. Meryemoğlu B, Hasanoğlu A, Irmak S, Erbatur O. Biofuel production by liquefaction of kenaf (Hibiscus cannabinus L.) biomass. Bioresource Technology, 2014, 151: 278-283

61. Ramsurn H, Gupta R B. Production of biocrude from biomass by acidic subcritical water followed by alkaline supercritical water twostep liquefaction. Energy \& Fuels, 2012, 26(4): 2365-2375

62. Brand S, Susanti R F, Kim S K, Hong-shik L, Kim J, Sang B I. Supercritical ethanol as an enhanced medium for lignocellulosic biomass liquefaction: influence of physical process parameters. Energy, 2013, 59(15): 173-182

63. Toor S S, Rosendahl L, Nielsen M P, Glasius M, Rudolf A, Iversen $\mathrm{S}$ B. Continuous production of bio-oil by catalytic liquefaction from wet distiller's grain with solubles (WDGS) from bio-ethanol production. Biomass and Bioenergy, 2012, 36: 327-332

64. Cheng S, D'cruz I, Wang M, Leitch M, Xu C C. Highly efficient liquefaction of woody biomass in hot-compressed alcohol-water co-solvents. Energy \& Fuels, 2010, 24(9): 4659-4667

65. Junming X U, Jianchun J I A $\mathrm{N} \mathrm{G}$, Weidi D A I, Yu X U. Liquefaction of sawdust in hot compressed ethanol for the production of bio-oils. Process Safety and Environmental Protection, 2012, 90(4): 333-338

66. Xu J, Jiang J, Hse C, Shupe T F. Effect of methanol on the liquefaction reaction of biomass in hot compressed water. Energy \& Fuels, 2013, 27(8): 4791-4795

67. Hu S, Li Y. Two-step sequential liquefaction of lignocellulosic biomass by crude glycerol for the production of polyols and polyurethane foams. Bioresource Technology, 2014, 161: 410-415

68. Hu S, Li Y. Polyols and polyurethane foams from base-catalyzed liquefaction of lignocellulosic biomass by crude glycerol: effects of crude glycerol impurities. Industrial Crops and Products, 2014, 57: 188-194

69. Briones R, Serrano L, Llano-Ponte R, Labidi J. Polyols obtained from solvolysis liquefaction of biodiesel production solid residues. Chemical Engineering Journal, 2011, 175(15): 169-175

70. Tymchyshyn M, Xu C C. Liquefaction of bio-mass in hotcompressed water for the production of phenolic compounds. Bioresource Technology, 2010, 101(7): 2483-2490

71. Mishra G, Saka S. Kinetic behavior of liquefaction of Japanese beech in subcritical phenol. Bioresource Technology, 2011, 102(23): 10946-10950

72. Xu J, Jiang J, Chungyun H, Todd F S. Renewable chemical feedstocks from integrated liquefaction processing of lingocellulosic materials using microwave energy. Green Chemistry, 2012, 14(10): $2821-2830$ 